\title{
Cervical cancer screening among adolescent girls in Lesotho: Levels and determinants
}

\author{
T Letuka, BA (Hons); N De Wet, $\mathrm{PhD}$ \\ Department of Demography and Population Studies, Faculty of Humanities, University of the Witwatersrand, Johannesburg, South Africa.
}

Corresponding author: T Letuka (t.dletuka@gmail.com)

\begin{abstract}
Background. International guidelines have discouraged screening of young women under the age of 21 for cervical cancer. However, a high screening rate is still evident among adolescent girls in Lesotho.

Objective. To explore the levels and determinants of cancer screening among adolescent girls in Lesotho.

Methods. This cross-sectional study used secondary data from the 2014 Lesotho Demographic and Health Survey collected from 1542 adolescent girls aged 15 - 19 years. Descriptive statistics, the chi-square test and a binary logistic regression model were used to analyse the data.

Results. Despite recommendations that adolescents should not screen for cervical cancer, results show that $15 \%$ of adolescent girls in Lesotho attend screening services. Adolescent girls from rural areas are less likely to screen than those from urban areas (odds ratio (OR) $0.22,95 \%$ confidence interval (CI) $0.07-0.68 ; p=0.009$ ). Marital status and level of education were significantly associated with cervical cancer screening among respondents; however, age at first sex was not statistically associated with screening among adolescent girls. Conclusion. With reference to international guidelines, the screening rate for cervical cancer is high among adolescents in Lesotho. Future studies should focus on why adolescents in Lesotho still screen for cervical cancer despite international recommendations discouraging screening before the age of 21 .
\end{abstract}

S Afr J Child Health 2018;12(2 Suppl 1):S63-S66. DOI:10.7196/SAJCH.2018.v12i2.1518

Sub-Saharan Africa is reported to have the highest incidence and mortality rates for cervical cancer. Approximately $70 \%$ of the world's burden of cervical cancer is in developing countries. ${ }^{[1]}$ In 2017, Mboumba Bouassa et al. ${ }^{[2]}$ reported that the incidence rate of cervical cancer in sub-Saharan Africa was increasing, with 75000 new cases being reported. Reports in Lesotho indicate that there are approximately 35 new cases per 100000 women per year. ${ }^{[3]}$ Moreover, cervical cancer ranks as the leading cause of female cancer deaths in Lesotho. ${ }^{[4]}$ There is little information regarding cervical cancer screening in Lesotho and one study that did focus on cervical cancer screening in the country, focused only on screening among women older than 20 years. ${ }^{[5]}$ The screening rate for cervical cancer among adolescent girls in Lesotho is therefore not known.

A number of studies refer to international guidelines discouraging screening of women under the age of 21 for cervical cancer. ${ }^{[-8]}$ In 2002, the American Cancer Society recommended that cervical cancer screening should start at age $21 .{ }^{[9]}$ However, despite this recommendation studies show that in some areas, including Lesotho, cervical cancer screening continues to be performed in adolescents. ${ }^{[4,10-12]}$ Continued screening among adolescents may be associated with psychological and emotional consequences these girls are not prepared for. ${ }^{[13]}$ Understanding levels of cancer screening among adolescent girls can therefore help to inform policy implementations regarding adolescent health. This study aims to explore the levels and determinants of cancer screening among adolescent girls in Lesotho, in order to serve as a guide to policy makers in light of current international recommendations.

Adolescents are considered to have a lower risk of being diagnosed with cervical cancer. A study by Henrique et al.$^{[14]}$ showed cytological abnormalities in adolescents to be approximately $2.6 \%$. The authors consequently recommended that adolescents should not be screened, as such abnormalities are rare among young women. In keeping with such recommendations, Datta and Saraiy $\mathrm{a}^{[15]}$ excluded women under 21 years from their study on cervical cancer screening among women who attended sexually transmitted disease clinics. However, despite these recommendations, some studies still include adolescents in their research. For example, a study conducted in Argentina reported that most screening services recommend starting Pap tests among girls between the age of 15 and 18 years. ${ }^{[16]}$ The authors further reported that health professionals in Argentina advise women to be screened when they become sexually active, regardless of age. ${ }^{[16]}$ The study also showed that socioeconomically disadvantaged girls have a lower chance of being screened. Similarly, in a study among women between the ages 16 and 21 years at a US academic institution, it was found that low socioeconomic status was associated with lower testing rates. ${ }^{[10]}$ The authors also found that young women who were sexually active requested Pap tests. ${ }^{[10]}$

Moreover, a study among adolescent girls in Mozambique found that education level was associated with knowledge of cervical cancer prevention. ${ }^{[17]}$ That study also found that married adolescent girls were more likely to be aware of cervical cancer prevention than single adolescent girls. ${ }^{[17]}$ Furthermore, Francis et al. ${ }^{[18]}$ note that access to medical care in developing countries is limited outside urban areas.

Screening for cervical cancer among adolescent girls appears to be variable. For example, Kruzikas et al. ${ }^{[19]}$ found that the rate of Pap smear testing was $3.8 \%$ for the age group $11-18$ years, whereas a study from Nova Scotia reported that $45 \%$ of women aged $15-19$ years have had a Pap test. ${ }^{[20]}$ Reports show that in Lesotho women under the age of 20 continue to be screened for cervical cancer. ${ }^{[4]}$

\section{Methods}

This study used secondary data from the individual recode file of the 2014 Lesotho Demographic and Health Survey (DHS). The study population was adolescent girls (15 - 19 years) and the sample size for this study was 1 542. Statistical software (Stata version 14) was used for statistical analysis, which included descriptive statistics, bivariate analysis and multivariate analysis. Frequency distributions were used to describe the sociodemograhic characteristics of the adolescent girls in this study. Bivariate analysis involved chi-square cross-tabulations to consider the relationship between cervical 
cancer screening and sociodemographic characteristics of the study population. As the outcome variable (cervical cancer screening) is dichotomous, a binary logistic regression model was used during multivariate analysis to examine the association between cervical cancer screening and other independent variables.

The rate of cervical cancer screening was assessed based on the responses $($ Yes/No) to the question whether a respondent has ever had a Pap smear, as included in the DHS. The independent variables considered in this analysis included: place of residence (urban/ rural); highest level of education (primary/higher); marital status (never in union/ever married); a three-category household wealth index (poor/middle/rich); and age at first sex (never had sex/8 - 14 years/15 - 19 years). The wealth index tertile was used as a proxy for socioeconomic status while age at first sex was used as a proxy for sexual history.

Table 1. Weighted frequency and percentage distribution of sociodemographic and socioeconomic characteristics of adolescent girls in Lesotho, DHS 2014

\begin{tabular}{ll}
\hline Characteristics & $\boldsymbol{n}(\%)$ \\
\hline Urban & $449(31.2)$ \\
Rural & $991(68.8)$ \\
Primary & $403(27.9)$ \\
Higher & $1037(72.1)$ \\
Marital status & \\
Never in union & $1175(81.6)$ \\
Previously/currently married & $265(18.4)$ \\
Poor & $482(33.5)$ \\
Middle & $478(33.2)$ \\
Rich & $480(33.3)$ \\
Age at first sex (years) & \\
Never had sex & $780(54.2)$ \\
8 - 14 & $86(6)$ \\
15 - 19 & $574(39.8)$ \\
Cervical cancer screening attendance & \\
No & $281(84.8)$ \\
Yes & $50(15.2)$
\end{tabular}

As the study used secondary data, no ethical approval was required. However, the survey protocol was reviewed and approved by the Research and Ethics Committee of the Lesotho Ministry of Health and the Institutional Review Board of ICF International. ${ }^{[21]}$

\section{Results}

More than two-thirds of the respondents (69\%) resided in rural areas, compared with $31 \%$ who lived in urban areas (Table 1). The majority of the respondents $(72 \%)$ had completed or were enrolled for higher education, while $28 \%$ had completed only primary education. The vast majority $(90 \%)$ of respondents were unemployed. Most of the respondents (82\%) had never been in union, while $18 \%$ were or have been. The respondents were almost equally distributed across the income categories defined for this study (34\% rich, 33\% poor, 33\% middle class). More than half of the adolescents (54\%) have never had sex, while $40 \%$ became sexually active between 15 and 19 years of age; only $6 \%$ became sexually active between the age of 8 and 14 years. Results showed that $85 \%$ of the respondents had never had a Pap smear.

Table 2 shows the analysis of cervical cancer screening among adolescent girls in Lesotho. The analysis shows that $22 \%$ of adolescent girls with a primary education have undergone screening compared with only about $10 \%$ of those with a higher education. Results also show that attending screening is not differentiated according to place of residence. In addition, $27 \%$ of adolescent girls who attended screening are or have been married, compared with $9 \%$ who have never been in a union. A similar proportion of girls from poor and middle-class households $(\sim 15 \%)$ attended screening, whereas $7 \%$ from rich households reported having had a Pap smear.

Table 3 shows the results from the logistic regression model. Adolescent girls from rural areas were significantly less likely to attend screening than those in urban areas (odds ratio (OR) 0.22 , $95 \%$ confidence interval (CI) $0.07-0.68 ; p=0.009$ ) while controlling for other variables. Adolescent girls with a higher education were significantly less likely to have a Pap smear than those with a primary education (OR $0.24,95 \%$ CI $0.08-0.68 ; p=0.008$ ) when other variables were controlled. Moreover, respondents who have been or are married were significantly more likely to attend a Pap test than those who have never been in a union (OR 7.08, 95\% CI 2.17 - 23.12; $p=0.001$ ) while controlling for other variables.

Table 2. Sociodemographic and socioeconomic characteristics of adolescent girls screened for cervical cancer in Lesotho, according to data from the Demographic and Health Survey, 2014

\begin{tabular}{|c|c|c|c|}
\hline Characteristics & Did not attend $(N=309), n(\%)$ & Attended $(N=42), n(\%)$ & $p$-value \\
\hline Place of residence & & & 0.914 \\
\hline Urban & $113(88.3)$ & $15(11.7)$ & \\
\hline Rural & $196(87.9)$ & $27(12.1)$ & \\
\hline Highest level of education & & & 0.007 \\
\hline Primary & $45(77.6)$ & $13(22.4)$ & \\
\hline Higher & $264(90.1)$ & $29(9.9)$ & \\
\hline Marital status & & & 0.000 \\
\hline Never in union & $259(91.5)$ & $24(8.5)$ & \\
\hline Previously/currently married & $50(73.5)$ & $18(26.5)$ & \\
\hline Household wealth index & & & 0.097 \\
\hline Poor & $81(85.3)$ & $14(14.7)$ & \\
\hline Middle & $109(85.2)$ & $19(14.8)$ & \\
\hline Rich & $119(92.9)$ & $9(7.1)$ & \\
\hline Age at first sex (years) & & & 0.212 \\
\hline Never had sex & $158(90.3)$ & $17(9.7)$ & \\
\hline $8-14$ & $18(78.3)$ & $5(21.7)$ & \\
\hline $15-19$ & $133(86.9)$ & $20(13.1)$ & \\
\hline
\end{tabular}


Table 3. Association between cervical cancer screening among adolescent girls in Lesotho and other socioeconomic and sociodemographic characteristics, according to data of the Demographic and Health Survey, 2014

\begin{tabular}{|c|c|c|}
\hline Variables & $\begin{array}{l}\text { aOR }(95 \% \mathrm{CI}), \\
(N=351)\end{array}$ & $p$-value \\
\hline \multicolumn{3}{|l|}{ Place of residence } \\
\hline Urban* & 1 & \\
\hline Rural & $0.22(0.07-0.68)$ & 0.009 \\
\hline \multicolumn{3}{|l|}{ Highest level of education } \\
\hline Primary* & 1 & \\
\hline Higher & $0.24(0.08-0.68)$ & 0.008 \\
\hline \multicolumn{3}{|l|}{ Marital status } \\
\hline Never in union* & 1 & \\
\hline Previously/currently married & $7.08(2.17-23.12)$ & 0.001 \\
\hline \multicolumn{3}{|l|}{ Household wealth index } \\
\hline Poor* & 1 & \\
\hline Middle & $1.32(0.47-3.68)$ & 0.599 \\
\hline Rich & $0.37(0.07-1.93)$ & 0.235 \\
\hline \multicolumn{3}{|l|}{ Age at first sex (years) } \\
\hline Never had sex ${ }^{*}$ & 1 & \\
\hline $8-14$ & $0.74(0.10-5.47)$ & 0.768 \\
\hline $15-19$ & $0.44(0.13-1.49)$ & 0.188 \\
\hline
\end{tabular}

\section{Discussion}

This study focused on the levels and determinants of cervical cancer screening among adolescent girls in Lesotho. Our results show that a high percentage of adolescent girls in Lesotho continue to receive screening services, contrary to international recommendations. This may be problematic, considering possible psychological and emotional complications associated with such screening. ${ }^{[13]}$ Our results also show that adolescent girls living in rural areas were less likely to attend screening compared with their urban counterparts, as also found in an earlier southern African study. ${ }^{[18]}$ Moreover, level of education was found to be significantly associated with cervical cancer screening. Adolescent girls with a higher education were found to be less likely to screen for cervical cancer, which could suggest that they are better informed about the possible negative implications associated with cervical cancer screening at young ages. ${ }^{[13]}$

Respondents who have been or are married were significantly more likely to attend screening than those who have never been in a union. This may suggest that, similar to the situation in Argentina, ${ }^{[16]}$ health practitioners in Lesotho encourage women to screen for cervical cancer when they become sexually active, regardless of age. Marriage has been used as a proxy for sexual activity. ${ }^{[22]}$ Our results show no association between socioeconomic status and screening rate, in contrast to some other studies. ${ }^{[10,16]}$ Furthermore, no association was found between age at first sex and cervical cancer screening, unlike the findings from a study in which cervical cancer screening among adolescents increased with a sexual history. ${ }^{[10]}$

\section{Study limitations and strengths}

As this was a cross-sectional study, causality could not be inferred. The question asking respondents to report their age when they first had sex was prone to sexual desirability because sexually active younger adolescents may be likely to report themselves as never having had sex. Despite these limitations, this study sheds light on an overlooked study area and therefore can contribute to the literature on cervical cancer screening among adolescent girls. It may help to inform policy decisions or recommendations regarding cervical cancer screening among adolescents in Lesotho.

\section{Conclusion}

A large proportion of adolescent girls in Lesotho continue to be screened for cervical cancer despite international recommendations against screening at a young age. The screening rate appears to be influenced by specific sociodemographic factors, namely marital status, place of residence and level of education. Both health practitioners and adolescent girls should be educated about the implications of starting screening before the age of 21 . Further research among local health practitioners is warranted to evaluate whether their knowledge of and attitude to cervical cancer screening among girls agree with internationally recommended guidelines. Future studies to examine the reasons for continued screening and specifically the association with certain sociodemographic factors are recommended.

Acknowledgements. The support of the DST-NRF Centre of Excellence in Human Development towards this research is hereby acknowledged. Opinions expressed and conclusions arrived at, are those of the authors and are not necessarily to be attributed to the CoE in Human Development. The authors gratefully acknowledge the support of the Demography and Population Studies Programme, Schools of Public Health and Social Sciences, Faculties of Health Sciences and Humanities, University of the Witwatersrand, Johannesburg, South Africa.

Author contributions. TL was responsible for the data collection and analysis and writing up the results. NdW contributed to drafting the manuscript and critical revision. Both authors read and approved the final manuscript.

Funding. None.

Conflicts of interest. None.

1. Compaore S, Ouedraogo CMR, Koanda S, Haynatzki G, Chamberlain RM, Soliman AS. Barriers to cervical cancer screening in Burkina Faso: Needs for patient and professional education. J Cancer Educ 2016;31(4):760-766. https:// doi.org/10.1007/s13187-015-0898-9

2. Mboumba Bouassa RS, Prazuck T, Lethu T, Jenabian MA, Meye JF, Bélec L. Cervical cancer in sub-Saharan Africa: A preventable noncommunicable disease. Expert Rev Anti Infect Ther 2017;15(6):613-627. https://doi.org/10.1 080/14787210.2017.1322902

3. World Health Organization. The launching of National Cervical Cancer Screening Program in Lesotho. http://www.afro.who.int/news/launching national-cervical-cancer-screening-program-lesotho (accessed 8 June 2018).

4. Bruni L, Barrionuevo-Rosas L, Albero G, et al. Human papillomavirus and related diseases in the world. Summary report. http://www.hpvcentre.net/ statistics/reports/XWX.pdf (accessed 8 June 2018).

5. Viens LJ, Clouston S, Messina CR. Women's autonomy and cervical cancer screening in the Lesotho Demographic and Health Survey 2009. Soc Sci Med 2016;150:23-30. https://doi.org/10.1016/j.socscimed.2015.12.009

6. Moscicki A-B, Cox JT. Practice improvement in cervical screening and management (PICSM): Symposium on management of cervical abnormalities in adolescents and young women. J Low Genit Tract Dis 2010;14(1):73-80. https://doi.org/10.1097/lgt.0b013e3181cec411

7. Boardman LA, Robison K. Screening adolescents and young women. Obstet Gynecol Clin North Am 2013;40(2):257-268. https://doi.org/10.1016/j. ogc.2013.02.007

8. Spiryda LB, Brown J, Zhang H, Burgis JT. Delaying Pap test screening in the adolescent population: An evidence-based approach. J Pediatr Adolesc Gynecol 2014;27(1):3-5. https://doi.org/10.1016/j.jpag.2013.03.008

9. Saslow D, Runowicz CD, Solomon D, et al. American Cancer Society guideline for the early detection of cervical neoplasia and cancer. CA Cancer J Clin 2002;52(6):342-362. https://doi.org/10.3322/canjclin.52.6.342

10. Summers SL, Petzel A, Anderson J, Kenton K. Cervical cancer screening rates in a chart review of adolescent patients at an academic institution before and after the publication of the 2009 American College of Obstetricians and Gynecologists recommendations. J Pediatr Adolesc Gynecol 2015;28(4):258262. https://doi.org/10.1016/j.jpag.2014.08.013

11. Korkidakis A, Bryson P, Jamieson MA. Outcomes of a decade of routine cervical screening in a Canadian adolescent obstetrics clinic. J Obstet Gynaecol Can 2016;38(1):51-55. https://doi.org/10.1016/j.jogc.2015.12.001

12. Vash-Margita A, Flagler EN, Kobernik EK, Quint EH, Dalton VK. Trends in cervical cancer screening in adolescents. J Pediatr Adolesc Gynecol 2017;30(2):293-294. https://doi.org/10.1016/j.jpag.2017.03.056

13. Committee on Practice Bulletins-Gynecology. ACOG Practice Bulletin Number 131: Screening for cervical cancer. Obstet Gynecol 2012;120(5):12221238. https://doi.org/10.1097\%2FAOG.0b013e318277c92a 
14. Henrique LQ, Campaner AB, d'Avila FS. Cervical cancer screening of adolescents should not be encouraged. J Low Genit Tract Dis 2017;21(1):21-25. https://doi.org/10.1097/lgt.0000000000000273

15. Datta SD, Saraiya M. Cervical cancer screening among women who attend sexually transmitted diseases (STD) clinics: background paper for 2010 STD Treatment Guidelines. Clin Infect Dis 2011;53 Suppl 3:S153-S159. https://doi. org/10.1093/cid/cir704

16. Arrossi S, Ramos S, Paolino M, Sankaranarayanan R. Social inequality in Pap smear coverage: Identifying under-users of cervical cancer screening in Argentina. Reprod Health Matters 2008;16(32):50-58. https://doi.org/10.1016/ S0968-8080(08)32410-0

17. Bardají A, Mindu C, Augusto OJ, et al. Awareness of cervical cancer and willingness to be vaccinated against human papillomavirus in Mozambican adolescent girls. Papillomavirus Res 2018;5:156-162. https://doi.org/10.1016/j. pvr.2018.04.004

18. Francis SA, Leser KA, Esmont EE, Griffith FM. An analysis of key stakeholders' attitudes and beliefs about barriers and facilitating factors in the development of a cervical cancer prevention program in South Africa. Afr J Reprod Health 2013;17(1):158-168.
19. Kruzikas D, Smith JS, Harley C, Buzinec P. Costs associated with management of cervical human papillomavirus-related conditions. Cancer Epidemiol Biomark Prev 2012;21(9):1469-1478. https://doi.org/10.1158/1055-9965.epi11-1019

20. Langille DB, Rigby JA. Factors associated with PAP testing in adolescents in northern Nova Scotia. Can J Public Health 2006;97(3):183-186.

21. Ministry of Health (Lesotho) and ICF International. Lesotho Demographic and Health Survey 2014. Maseru: Ministry of Health Lesotho and ICF International, 2016. http://dhsprogram.com/publications/publication-fr309dhs-final-reports.cfm (accessed 8 June 2018).

22. Bongaarts J. A framework for analyzing the proximate determinants of fertility. Popul Dev Rev 1978;4(1):105-132. https://doi.org/10.2307/1972149 